\title{
Adult Empathy: Possible Gender Differences in Gene-Environment Architecture for Cognitive and Emotional Components in a Large Italian Twin Sample
}

\author{
Virgilia Toccaceli, ${ }^{1, *}$ Corrado Fagnani, ${ }^{1, *}$ Nancy Eisenberg, ${ }^{2}$ Guido Alessandri, ${ }^{3}$ Augusto Vitale, ${ }^{1}$ \\ and Maria Antonietta Stazi ${ }^{1}$ \\ ${ }^{1}$ Center for Behavioral Sciences and Mental Health, Italian National Institute of Health, Rome, Italy \\ ${ }^{2}$ Department of Psychology, Arizona State University, Tempe, Arizona, USA \\ ${ }^{3}$ Department of Psychology, Sapienza, University of Rome, Rome, Italy
}

\begin{abstract}
Empathy plays a central role in prosocial behavior and human cooperation. Very few twin researchers have investigated innate and environmental effects in adult empathy, and twin research on gender differences in these effects is sparse. The goal of this study was to examine innate and environmental influences on three components of an empathy scale frequently used with adults - the expression of cognitive (CE), emotional (EE), and social skills (SS) empathy - and to explore gender differences in the influences. Study participants were $\sim 1,700$ twins (18-65 years) enrolled in the Italian Twin Registry. Empathy was assessed with the Italian version of the Empathy Quotient (EQ), for which the three-factor structure (i.e., $C E$, EE, and SS) was confirmed. Twin correlations in monozygotic and dizygotic pairs, and males and females were estimated for the total EQ and subscale scores, and univariate genetic model fitting was carried out. Women's empathy (i.e., total $E Q$ as well as $C E$ and $E E$ subdimensions) was predominantly driven by genetic factors and individual experiences, whereas for males, no genetic contribution or important shared and individual environmental effects emerged. Although of large magnitude, the gender differences did not reach statistical significance. Age did not moderate empathy heritability in adulthood. Only for the SS subscale were genetic and environmental proportions of variance similar for men and women. This study suggests possible gender-specific innate and environmental influences on empathy and its cognitive and emotional components that need to be confirmed in future studies.
\end{abstract}

Keywords empathy, gender differences, twin study, heritability, environmental factors

'Empathy' has been defined as the ability or competence to share the feelings of others (Decety \& Lamm, 2006; Saudino et al., 2008). Baron-Cohen's (2002) definition includes additional competencies: 'the drive to identify another person's emotions and thoughts, and to respond to these with an appropriate emotion' (p. 248). The complexity of empathy from both phylogenetic and ontogenetic perspectives is clear from different, intertwined scientific areas of investigation such as developmental and social psychology, cognitive neuroscience, clinical neuropsychology, and behavioral evolution (Baron-Cohen \& Wheelwright, 2004; Blair, 2005; Davis et al., 1994; Decety \& Jackson, 2004; Decety \& Lamm, 2006; de Waal, 2008; Preston \& de Waal, 2002).

In evolutionary terms, prosocial behaviors can be observed in different species of non-human primates; in particular, in those species in which individuals live in close social systems, such as the common marmoset (Callithrix jacchus; Burkhart et al., 2007; see also Cronin, 2012). Empathy can find its evolutionary roots in different forms of observed prosocial behavior. In fact, de Waal (2012) argues that empathy could be the main motivator of prosocial behaviors in different species of primates. These observations suggest that prosociality and empathy have,

RECEIVED 23 January 2018; ACCEPTED 14 March 2018. First published online 15 April 2018.

ADDRESS FOR CORRESPONDENCE: Virgilia Toccaceli, Center for Behavioral Sciences and Mental Health, Italian National Institute of Health, Viale Regina Elena, 299-00161 Rome, Italy. E-mail: virgilia.toccaceli@iss.it

* These authors contributed equally to the work. 
in fact, a phylogenetic history. However, the complexity of prosocial behavior and empathy manifestations in humans does not find correspondence in other species. Indeed, empathy likely plays a central role in the development and occurrence of prosocial behavior in humans. Investigators have frequently recognized the role of empathy-related responding in facilitating human cooperation (Eisenberg \& Miller, 1987), and have suggested that empathy provides a major pathway to prosocial functioning (Batson, 1991; Batson et al., 2004; de Waal, 2008). Individual differences in empathy-related responding levels have been recorded among individuals of all ages, in infancy (Knafo et al., 2008), in childhood (Bryant, 1982), and in adulthood (Lawrence et al., 2004). However, few researchers have investigated the role of genetic and environmental factors in the expression of the trait in adulthood (Knafo \& Uzefovsky, 2013).

Individuals who are higher in empathy during childhood, regardless of gender, tend to remain higher later in development, demonstrating the stability of this trait (Eisenberg et al., 1999; 2002). Such evidence is consistent with the idea that empathy is partially heritable (e.g., BaronCohen, 2002; Chakrabarti \& Baron-Cohen, 2013; Knafo et al., 2008; Rushton, 2004; Zahn-Waxler, Radke-Yarrow et al., 1992; Zahn-Waxler, Robinson et al., 1992; ZahnWaxler et al., 2001) or at least that there are some evolutionary differences already present at birth. Furthermore, from twin studies comes the strongest evidence that empathy is heritable and that the heritability increases with age (Davis et al., 1994; Hatemi et al., 2015; Hur, 2007; Knafo et al., 2008; Rushton, 2004; Rushton et al., 1984).

It is also hypothesized that the well-known gender differences in empathy levels, favoring females (Baron-Cohen, 2002; Eisenberg \& Lennon, 1983; Sucksmith et al., 2013; Volbrecht et al., 2007), may have an evolutionary origin due to the emergence of animal species characterized by K-selection (i.e., those species characterized by prolonged and intensive parental care facilitated by the fact that mothers have relatively few children). With this strategy, mothers tend to be in tune with the expression of discomfort displayed by the infants, perhaps in part due to their ability to spend considerable time in close contact with their offspring. Given this framework, an important question might be whether gender differences in human empathy can be mirrored by the pattern of heritability for empathy traits. According to the empathizing-systemizing theory (BaronCohen, 2009), which defines five different 'brain types' with the 'systemizing profile' more common in males and the 'empathizing profile' more common in females, it appears crucial to generate more knowledge on possible genderspecific contributions of innate and environmental factors to empathy-related functioning in adult life, taking into account the potential influence of age.

Thus, our research was designed (1) to shed light on the possible contributions of innate and environmental factors in the empathy-related expression in adulthood, looking at the emotional, cognitive, and social components delineated within the trait (Berthoz et al., 2008; Dimitrijevic et al., 2012; Groen et al., 2015; Lawrence et al., 2004; Muncer \& Ling, 2006; Preti et al., 2011) and (2) to explore possible gender differences in these contributions.

To pursue our objectives, we applied the twin study design to a large sample drawn from the population-based Italian Twin Registry (ITR) (Brescianini et al., 2013). The twin design has shed light on the causal mechanisms underlying an extraordinary variety of complex phenotypes and diseases, including psychosocial traits (Gregory et al., 2009; Knafo et al., 2008), and its potential has enormously increased since the worldwide spread of twin registries (Hur \& Craig, 2013). This design allows for the estimation of genetic and environmental effects on the expression of human complex traits by comparing the level of trait resemblance between monozygotic (MZ) twins (genetically identical) and dizygotic (DZ) twins (who share on average only $50 \%$ of their genetic background, like ordinary siblings). Briefly, assuming that $\mathrm{MZ}$ and $\mathrm{DZ}$ twins share to the same extent all environmental exposures that are relevant to the trait under study (Equal Environments Assumption), a higher resemblance in MZ than in DZ pairs would point to genetic influences on the trait; if, instead, resemblance is not dependent upon zygosity, then environmental factors (family-based or individual-specific) would be supported as primary influences on trait expression (Neale \& Cardon, 1992).

It is important to point out that the twin studies that have previously assessed the heritability of empathy (variously measured) among adults and young adults (e.g., Davis et al., 1994; Hur, 2007; Rushton, 2004; Rushton et al., 1984) have not focused on possible gender differences, except for one study conducted by Hatemi et al. (2015). In a sample of young-adult twins in Australia, they found that individual differences in men's empathy, measured through the EQ, were largely due to genetic influences, and those in women's empathy almost entirely explained by non-shared environmental factors or error; however, they did not analyze the empathy subdimensions of the EQ. It may be hypothesized that gender differences in a psychosocial trait such as empathy vary as a function of gender differences in a given culture; thus, it is useful to examine these differences in a country like Italy, where different socialization and social roles for men and women have been maintained, perhaps more so than in some other Western countries.

\section{Materials and Methods}

\section{Sample, Procedures and Measures}

Study participants were recruited from a large multipurpose survey (Toccaceli et al., 2014) on twins aged 18-65 years who had been enrolled in the population-based ITR over a period of nearly 12 years, from 2001 to 2012 . It is important to point out that twins as individuals often have not differed from non-twins with respect to social and behavioral 
characteristics (e.g., Klemmensen et al., 2012); therefore, it is reasonable to consider that our results might be generalized to the general population as well. The procedures that led to the establishment of the ITR are described in detail elsewhere (Brescianini et al., 2013). Currently, the ITR contains information on approximately 28,000 twins, and is involved in both general population and clinical-based studies on various complex phenotypes, with behavioral and psychiatric genetics as major research areas.

Between June and October 2012, 4,894 adult twins aged 18-65 years were contacted by mail and were asked to participate in the survey. The mailed material included a brief letter explaining the aims of the survey, as well as an informed consent form that the respondents had to return separately in order to safeguard individuals' privacy and confidentiality. In the same contact, the twins received the questionnaire for the assessment of empathy.

Empathy assessment. Empathy was assessed with the Italian version (Preti et al., 2011) of the Empathy Quotient (EQ; Baron-Cohen \& Wheelwright, 2004). The EQ is a wellknown instrument comprised of 60 items (40 items tapping empathic behavior and 20 filler items not counted in the scoring). The EQ items are rated on a four-point Likert scale ( 1 = strongly agree to $4=$ strongly disagree). A large number of studies have previously validated the EQ by demonstrating the typical gender differences in various European countries (Dimitrijevic et al., 2012; Preti et al., 2011; Vellante et al., 2013; Von Horn et al., 2010; Zeyer et al., 2012), in Canada and the United States (Berthoz et al., 2008; Wright \& Skagerberg, 2012) and, to a minor extent, in Asian countries (Kim \& Lee, 2010; Wakabayashi et al., 2007). Following Baron-Cohen and Wheelwright (2004), a three-point scoring system was adopted, in which the 21 forward items were scored 2 for strongly agree, 1 for slightly agree, and 0 for strongly disagree and slightly disagree, while the 19 reversed items were scored 2 for strongly disagree, 1 for slightly disagree, and 0 for strongly agree and slightly agree. According to this system, scores can range from 0 to 80 , with a cut-off of 30 that best differentiates between mean levels of empathy in the general population and autism spectrum conditions. The original version of the EQ has shown adequate internal consistency, concurrent and convergent validity, and good test-retest reliability (Baron-Cohen \& Wheelwright, 2004; Lawrence et al., 2004). High validity of the instrument has been reported also in the Italian population (Preti et al., 2011). Moreover, previous studies using a factor-analytic approach, based either on 28 items or on 15 items (Berthoz et al., 2008; Dimitrijevic et al., 2012; Groen et al., 2015; Lawrence et al., 2004; Muncer \& Ling, 2006; Preti et al., 2011), but not the 40-item version, have identified three EQ subscales labeled 'cognitive empathy' (CE; i.e., items that tap the ability to effectively understand the emotions of another individual and assume his/her perspective; Volbrecht et al., 2007), 'emotional empathy' (EE; i.e., items that tap the individual's emotional response to another's expressed emotion; Duan \& Hill, 1996), and 'social skills' (SS; i.e., items that tap the sensitivity to social situations through, for example, the presence of spontaneous use of SS and of intuitive social understanding; Lawrence et al., 2004; Muncer \& Ling, 2006). Therefore, besides calculating a global score for the individual proneness to empathy based on the full (40-item) version, we also conducted subdimension analyses based on the 28-item EQ scale.

Moderating and control variables. It was hypothesized that gender differences in the levels of empathy may reflect gender-specific genetic and environmental effects on empathic behavior; therefore, model-fitting analyses were stratified by gender. Furthermore, given the wide age range (18-65 years) of the study sample, possible interactions of age with genetic and environmental influences were also tested. Because no age moderation emerged, interindividual age differences were simply considered a potential confounding factor and were controlled for in modelfitting analyses (see Statistical Analyses).

\section{Statistical Analyses}

For sample descriptives, confirmatory factor analyses (CFA), reliability, gender differences, and correlation with the autism spectrum quotient (AQ), twins from both complete and unmatched pairs were used and were considered as individual subjects.

The socio-demographic background of the sample in terms of age, gender, education, and marital status was examined using Stata (version 13.0).

Confirmatory factor analyses (CFA). In order to determine whether the three-factor structure of the EQ (i.e., CE, $\mathrm{EE}$, and SS) could be replicated in this Italian sample, factor analysis was conducted in $\mathrm{R}$ (version 3.1.0) by using the 'lavaan' package. The following separate CFA were performed for the 40 -item and the 28 -item version (Lawrence et al., 2004): (1) one-factor model for the 40-item version, (2) one-factor model for the 28 -item version, and (3) threefactor model (CE: 11 items; EE: 11 items; and SS: 6 items) for the 28-item version. The three-factor model was tested only for the short 28-item version because no factor structure had been proposed by previous studies for the EQ containing all original 40 items. The Diagonally Weighted Least Square method of estimation was applied in all CFAs, given the ordered categorical response format. All the models were evaluated using the following indices: normed chisquare (i.e., chi-square/df), the root mean squared error of approximation (RMSEA) with its $90 \%$ confidence interval (CI), and the comparative fit index (CFI). Recommended values for these measures are between 2 and 5 for the normed chi-square (Hooper et al., 2008), below 0.08 for the RMSEA (Hooper et al., 2008), and above 0.90 for the CFI (Hu \& Bentler, 1999). The metric invariance of the threefactor model (i.e., CE, EE, and SS) by gender was assessed 
by first fitting a two-group, three-factor model to both genders simultaneously (configural model) and then evaluating the chi-square change when equating factor loadings between males and females. To check whether the nonindependence of data within twin pairs affected the results, all CFAs were first conducted on the total sample of twins and were then replicated considering only twin-1 and only twin-2 in each pair.

Reliability. The internal consistencies of the EQ scale and its subscales (CE, EE, and SS) were estimated in R (version 3.1.0) by the Cronbach's alpha and the McDonald's omega in their ordinal versions (Gadermann et al., 2012; Zumbo et al., 2007), considering as acceptable those values higher than 0.70 (DeVellis, 2012). Possible effects of withinpair data clustering were inspected by performing separate reliability analyses on the twin-1 sample and the twin-2 sample.

Gender differences analyses and the correlation of EQ with the autism-spectrum quotient. Gender differences for the total EQ (both 40-item and 28-item version) were tested with an independent-samples $t$-test in its clusteradjusted version to account for the non-independence of observations within twin pairs. Between-gender comparisons were also performed for the EQ subscales (CE, EE, and SS). The correlation between the EQ score and the AQ score (Baron-Cohen et al., 2001) was estimated using the Pearson's correlation coefficient; this latter analysis was performed on a subsample of twins who had been administered the AQ questionnaire in a previous study by our group (Picardi et al., 2015). Gender differences analyses and correlation with the AQ were carried out with Stata (version 13.0).

The following analyses (i.e., twin correlations and genetic model fitting) were based on complete twin pairs only, and were conducted with the Mx statistical software (version 1.7.03; Neale et al., 2006) using raw data as input.

Twin correlations. For the total EQ and subscales (CE, EE, and SS) scores, the within-pair correlations between the twin-1 and twin-2 samples were estimated according to zygosity (MZ vs. DZ pairs) and gender, and were interpreted under the assumptions of the twin design (Neale \& Cardon, 1992). This was achieved by fitting multigroup saturated models that allowed different parameters (means, variances, and covariances) for MZ and DZ pairs, and for males and females, so containing five zygosity-by-gender groups (MZ male, DZ male, MZ female, DZ female, and DZ unlike-gender pairs).

In order to gain insights into the complex interplay of empathy facets and to test whether this interplay could affect gender differences in the genetic and environmental components, the within-individual phenotypic correlations between the EQ subscales (CE, EE, and SS) were also estimated by multivariate multigroup saturated models.
Genetic model fitting. Univariate gender-limitation structural equation models (Neale \& Cardon, 1992) with five zygosity-by-gender groups (see above, 'Twin correlations') were fitted to estimate genetic and environmental effects on the total EQ and subscales (CE, EE, and SS) scores. In particular, total variance in the scores was decomposed into the following components: (1) additive genetic variance (A), resulting from the additive effects of all loci relevant to the trait; (2) shared environmental variance $(C)$, representing the influence of environmental factors that are shared by the twins, especially within the family during early childhood (e.g., socio-economic status of the family, cultural background and practice, parents' job, and parents' childrearing style), but possibly also during prenatal life; and (3) unshared environmental variance (E), due to acquired experiences that are unique to an individual (e.g., traumatic events, health status, social engagement, education level, chance friendships, and job experience), including measurement error effects. Gender-specific proportions of total variance explained by each of the above components were calculated, with the additive genetic proportion known as the trait 'heritability'; these proportions were used to summarize the genetic-environmental influences on empathic behavior (i.e., total EQ and subscales) in men and women, and to perform gender comparisons. Given that statistical power issues may seriously affect model selection, we considered it prudent to avoid submodel fitting and to report the estimates under the full (ACE) model for both genders. Possible age-related modification of genetic and environmental effects on the EQ scales was also tested by interaction models (Purcell, 2002) that incorporated age as a continuous moderator to avoid arbitrary categorizations.

\section{Results}

Data from 1,687 individual twins (corresponding to $34 \%$ of the survey population) were analyzed; of these, 445 were unmatched twins because the co-twin did not respond to the survey. The demographic background (i.e., age, gender, education, and marital status) of the study sample did not differ from that of non-respondents and is shown in Table 1 . Individuals were aged $18-65$ years $\left(M_{\text {age }}=39\right.$ years, $S D=14$ years), with men representing $39 \%$ of the sample. A proportion of $12 \%$ of the sample completed only secondary school, $40 \%$ high school, and 38\% college or university (3year and 5-year degree); $53 \%$ of the twins were unmarried.

\section{Confirmatory Factor Analyses (CFA)}

Table 2 presents the (standardized) item loadings and the goodness-of-fit statistics of the CFAs applied to the 40-item version (one-factor model) and to the 28 -item version (onefactor and three-factor model) of the EQ. The CFA supported the previously proposed three-factor structure of the EQ in the 28-item version. The item loadings of the threefactor model ranged from 0.53 to 0.79 for the CE factor, 


\section{TABLE 1}

Socio-Demographic Characteristics of the Study Sample

\begin{tabular}{lcc}
\hline Variables & $N(\%)$ & Mean (range) \\
\hline Age (years) & & \\
Gender & & \\
Male & $661(39.2)$ & \\
Female & $1,026(60.8)$ \\
Education & $231(13.7)$ \\
Primary/secondary school & $142(8.4)$ & \\
Vocational school & $671(39.8)$ \\
High school & $153(9.1)$ & \\
3-year degree & $481(28.5)$ \\
5-year degree & $9(0.5)$ & \\
Missing & & \\
Marital status & $895(53.1)$ \\
Single & $584(34.6)$ \\
Married & $103(6.1)$ & \\
Living in couple & $41(2.4)$ & \\
Separated & $44(2.6)$ & \\
Divorced & $12(0.7)$ & \\
Widowed & $8(0.5)$ & \\
Missing &
\end{tabular}

from 0.17 to 0.87 for the EE factor, and from 0.47 to 0.73 for the SS factor. All items of the three-factor model, except three, had loadings $\geq 0.30$. Item loadings of the onefactor model ranged from 0.01 to 0.76 (40-item version) and from 0.13 to 0.77 (28-item version). Whereas the onefactor model of the 28 -item version contained six items with loadings $<0.30$, the one-factor model of the 40 -item version contained 13 such items. The three-factor model on the 28item version clearly fit the data better than the one-factor models (40-item and 28-item version).

As a reassurance that our results on the 28 -item version provided a faithful picture of the full version, an exploratory factor analysis on the 40-item EQ revealed three factors explaining $93 \%$ of the variance in the data; these empirical factors overlapped considerably with the CE, EE, and SE components previously identified (data not shown).

The three-factor model showed metric invariance by gender; indeed, constraining factor loadings of the two-group configural model (goodness of fit: chisquare $/ d f=2.43$, RMSEA $=0.043, \mathrm{CFI}=0.92$ ) to be equal between males and females yielded a non-significant ( $p=.75)$ increase of the chi-square. The clustering of observations within the twin pairs did not seem to affect the results of CFAs because these results remained unchanged when the analyses were replicated using twin- 1 and twin-2 samples separately (data not shown).

\section{Reliability}

The internal consistencies of the 40-item and 28-item EQ (Cronbach's alpha $=0.88$ and 0.90 , respectively; McDonald's omega $=0.87$ and 0.90 , respectively) and of the subscales of the 28-item EQ (Cronbach's alphas $=0.91$ [CE], 0.79 [EE], and 0.79 [SS]; McDonald's omegas $=0.91$ [CE], 0.79 [EE], and $0.80[\mathrm{SE}]$ ) were good. The higher internal consistency of the CE subscale compared to the EE and SS subscales was in line with previous reports showing that reversed items ( 0 out of 11 for CE, 6 out of 11 for EE, 4 out of 6 for SS) were less reliable than forward items (Groen et al., 2015). Results of reliability analyses on twin-1 and twin-2 samples were almost identical (data not shown).

\section{Gender Differences Analyses and the Correlation of EQ with the $A Q$}

Gender-specific means and standard deviations of the 40item EQ and the 28-item EQ with its subscales are reported in Table 3. The expected gender differences in mean level were detected, with women showing significantly higher scores than men on the 40-item and 28-item EQ. With regard to the EQ subscales, the largest gender difference was found for EE followed by CE, with significance reached for both subscales; for SS, men's and women's scores were similar and were no longer significantly different. The same gender pattern held true when stratifying the sample by age; more precisely, in each of the three age-groups 18-25, 2650, and 51-65 years the levels of the 40-item and 28-item $\mathrm{EQ}$, as well as of the CE and EE subscales, remained significantly higher for women, whereas similar levels of the SS subscale were observed across genders. The mean values for men and women for the 40-item EQ in the 18-25 age group were in line with those reported by Preti et al. (2011) for an Italian sample of students aged 18 to 30 years.

For a subsample of 99 twins with available data on the $\mathrm{AQ}$, the AQ score was negatively correlated with both the 40-item EQ $(r=-0.44)$ and the 28-item EQ score $(r=-$ $0.46)$. These data may provide slight support for the divergent validity of the EQ.

\section{Twin Correlations}

The responders were 1,242 twins from complete pairs and 445 unmatched twins, for a total 1,687 subjects. Correlation analyses (and genetic model fitting, below) were based on 606 complete pairs with available information on zygosity, after excluding 15 pairs of unknown zygosity. Of the 606 pairs, 117 were MZ male, $53 \mathrm{DZ}$ male, $193 \mathrm{MZ}$ female, 113 DZ female, and $130 \mathrm{DZ}$ unlike gender. Table 4 shows the within-pair correlations between twin- 1 and twin-2 samples in the five zygosity-by-gender groups. For the 40-item and 28-item EQ, the difference between the correlations in $\mathrm{MZ}$ and same-gender $\mathrm{DZ}$ pairs was less for men than for women; furthermore, DZ unlike-gender pairs were substantially less correlated than were DZ same-gender pairs. This suggested possible gender differences in the underlying genetic-environmental architecture of empathic behavior as measured by the total EQ (both 40 -item and 28 -item version). In particular, the correlational pattern seemed consistent with a weaker or absent role of the shared environment in women. Inspection of the correlations for the two zygosity groups for each of the EQ subscales suggests that the gender differences might be driven by the 
TABLE 2

Standardized Item Loadings and Goodness-of-Fit Indices of the Confirmatory Factor Analysis (CFA) of the EO

\begin{tabular}{|c|c|c|c|}
\hline Item & $\begin{array}{l}\text { One-factor } \\
\text { (40 items) }\end{array}$ & $\begin{array}{l}\text { One-factor } \\
\text { (28 items) }\end{array}$ & $\begin{array}{l}\text { Three-factor } \\
\text { (28 items) }\end{array}$ \\
\hline 1. I can easily tell if someone else wants to enter a conversation. & 0.63 & 0.63 & $0.65(\mathrm{CE})$ \\
\hline 25. I am good at predicting how someone will feel. & 0.67 & 0.70 & 0.73 (CE) \\
\hline 26. I am quick to spot when someone in a group is feeling awkward or uncomfortable. & 0.70 & 0.71 & 0.73 (CE) \\
\hline $\begin{array}{l}\text { 36. Other people tell me I am good at understanding how they are feeling and what } \\
\text { they are thinking. }\end{array}$ & 0.76 & 0.77 & 0.79 (CE) \\
\hline 44. I can sense if I am intruding, even if the other person doesn't tell me. & 0.57 & 0.59 & $0.63(\mathrm{CE})$ \\
\hline 52. I can tune into how someone else feels rapidly and intuitively. & 0.73 & 0.75 & 0.77 (CE) \\
\hline 54. I can easily work out what another person might want to talk about. & 0.68 & 0.71 & 0.73 (CE) \\
\hline 55. I can tell if someone is masking their true emotion. & 0.63 & 0.67 & 0.69 (CE) \\
\hline 58. I am good at predicting what someone will do. & 0.45 & 0.51 & 0.53 (CE) \\
\hline 6. I really enjoy caring for other people. & 0.41 & 0.40 & $0.48(\mathrm{EE})$ \\
\hline 21. It is hard for me to see why some things upset people so much (R). & 0.17 & 0.13 & $0.17(\mathrm{EE})$ \\
\hline 22. I find it easy to put myself in somebody else's shoes. & 0.64 & 0.63 & $0.87(\mathrm{EE})$ \\
\hline 29. I can't always see why someone should have felt offended by a remark (R). & 0.34 & 0.30 & $0.42(\mathrm{EE})$ \\
\hline 32. Seeing people cry doesn't really upset me (R). & 0.30 & 0.26 & $0.35(\mathrm{EE})$ \\
\hline 42. I get upset if I see people suffering on news programs. & 0.29 & 0.26 & 0.35 (EE) \\
\hline $\begin{array}{l}\text { 43. Friends usually talk to me about their problems as they say I am very } \\
\text { understanding. }\end{array}$ & 0.65 & 0.64 & $0.85(\mathrm{EE})$ \\
\hline 48. Other people often say that I am insensitive, though I don't always see why (R). & 0.43 & 0.34 & $0.44(\mathrm{EE})$ \\
\hline 50. I usually stay emotionally detached when watching a film (R). & 0.24 & 0.21 & $0.28(\mathrm{EE})$ \\
\hline 59. I tend to get emotionally involved with a friend's problems. & 0.40 & 0.38 & $0.51(\mathrm{EE})$ \\
\hline $\begin{array}{l}\text { 4. I find it difficult to explain to others things that I understand easily, when they } \\
\text { don't understand it first time (R). }\end{array}$ & 0.32 & 0.29 & 0.47 (SS) \\
\hline 8. I find it hard to know what to do in a social situation (R). & 0.48 & 0.47 & 0.73 (SS) \\
\hline $\begin{array}{l}\text { 12. Friendships and relationships are just too difficult, so I tend not to bother with } \\
\text { them (R). }\end{array}$ & 0.41 & 0.39 & 0.59 (SS) \\
\hline 14. I often find it difficult to judge if something is rude or polite (R). & 0.44 & 0.40 & 0.62 (SS) \\
\hline 35. I don't tend to find social situations confusing. & 0.44 & 0.46 & 0.68 (SS) \\
\hline 57. I don't consciously work out the rules of social situations. & 0.45 & 0.43 & $0.66(\mathrm{SS})$ \\
\hline 10. People often tell me that I went too far in driving my point home in a discussion (R). & 0.16 & & \\
\hline 18. When I was a child, I enjoyed cutting up worms to see what would happen (R). & 0.01 & & \\
\hline $\begin{array}{l}\text { 28. If anyone asked me if I like their haircut, I would reply truthfully, even if I didn't like } \\
\text { it (R). }\end{array}$ & 0.05 & & \\
\hline $\begin{array}{l}\text { 34. I am very blunt, which some people take to be rudeness, even though this is } \\
\text { unintentional (R). }\end{array}$ & 0.10 & & \\
\hline 37. When I talk to people, I tend to talk about their experiences rather than my own. & 0.22 & & \\
\hline 38. It upsets me to see animals in pain. & 0.25 & & \\
\hline 39. I am able to make decisions without being influenced by people's feelings (R). & 0.23 & & \\
\hline 46. People sometimes tell me that I have gone too far with teasing $(R)$. & 0.25 & & \\
\hline $\begin{array}{l}\text { 49. If I see a stranger in a group, I think that it is up to them to make an effort to join in } \\
\text { (R). }\end{array}$ & 0.31 & & \\
\hline $\begin{array}{l}\text { 60. I can usually appreciate the other person's viewpoint, even if I don't agree with it. } \\
\text { Goodness-of-fit indices }\end{array}$ & 0.38 & & \\
\hline - normed chi-square & 9.91 & 10.98 & 5.74 \\
\hline - RMSEA & 0.076 & 0.080 & 0.055 \\
\hline - $90 \%$ Cl-RMSEA & $0.075 ; 0.078$ & $0.077 ; 0.082$ & $0.052 ; 0.058$ \\
\hline$\cdot \mathrm{CFI}$ & 0.74 & 0.86 & 0.93 \\
\hline
\end{tabular}

Note: $\mathrm{R}=$ reversed item; $\mathrm{CE}=$ cognitive empathy subscale; $\mathrm{EE}=$ emotional empathy subscale; $\mathrm{SS}=$ social skills subscale; $\mathrm{RMSEA}=$ root mean squared error of approximation; $90 \%$ CI-RMSEA $=90 \%$ confidence interval of RMSEA; CFI = comparative fit index.

cognitive and emotional components, whereas the correlations for the social component seemed to indicate similar genetic and environmental effects for men and women.

Table 4 also shows that the correlations among the 28item EQ subscales by gender were of similar magnitude for men (about 0.40) and women (range: 0.33-0.36). Furthermore, based on the twin design, higher cross-twin/crosstrait correlations (i.e., between one component in twin 1 and another component in twin 2) in MZ female compared to DZ female pairs support a possible genetic correlation between the empathy subdimensions in women.

\section{Genetic Model-Fitting}

Interaction analyses showed no moderation by age of the genetic and environmental proportions of variance for any of the EQ scales for either gender, confirming that age simply acted as a potential confounding factor for empathy heritability. With regard to age differences in level of empathy, 


\section{TABLE 3}

Summary Statistics of the EQ Scales by Gender

\begin{tabular}{|c|c|c|c|c|c|}
\hline \multirow[b]{2}{*}{ EQ scales } & \multicolumn{2}{|c|}{ Males } & \multicolumn{2}{|c|}{ Females } & \multirow[b]{2}{*}{$p^{*}$} \\
\hline & $N$ & Mean (SD) & $N$ & Mean (SD) & \\
\hline 40-item EQ & 645 & 41.9 (10.6) & 1,007 & $47.9(10.3)$ & $<.001$ \\
\hline 28-item EQ & 645 & $30.3(9.1)$ & 1,006 & $34.6(8.6)$ & $<.001$ \\
\hline CE & 645 & $11.9(4.7)$ & 1,006 & $13.1(4.7)$ & $<.001$ \\
\hline $\mathrm{EE}$ & 645 & $11.6(4.0)$ & 1,004 & $14.5(3.7)$ & $<.001$ \\
\hline SS & 644 & $6.9(3.1)$ & 1,009 & 7.1 (2.9) & .278 \\
\hline
\end{tabular}

Note: $C E$ = cognitive empathy subscale; $E E$ = emotional empathy subscale; $\mathrm{SS}=$ social skills subscale.

For each EQ scale, missing items' scores were replaced with the mean scores over available items when the number of missings did not exceed $10 \%$ of the total number of items (i.e., four missings for the 40 item EQ, three missings for the 28-item EQ, and one missing for each of the $C E, E E$, and $E E$ subscales).

* $p$ value for $t$-test on means (the test was performed with robust regression analysis - as implemented in Stata [version 13.0] — adjusted for age and accounting for within-pair clustering of observations).

a slight but non-significant inverse- $U$-shaped age pattern was observed in both genders, as already found in a previous study (O'Brien et al., 2013). Moreover, the quadratic effect (i.e., the square of age) played no role in the models for the estimation of twin correlations and heritability, and thus linear age was retained as the only covariate in these models. Genetic and environmental proportions of variance for all the empathy subscales, as obtained from the gender-limitation structural equation models, are reported in Table 5. Consistent with the pattern in the correlation analyses, for the 40-item and 28-item EQ, additive genetic factors explained marginal portions of variance (about 5\% and $10 \%$, respectively) in men's empathy, whereas they explained a substantial amount of variance (about 50\%) in women's empathy. Accordingly, the environmental load was higher for men's than for women's empathy; specifically, $40 \%$ of variance in men's empathy was due to the shared environment, whereas this factor accounted for no variance in women's empathy. The unshared environmental proportions of variance in men's and women's empathy were similar for the 40 -item EQ (56\% and 47\%, respectively) and identical for the 28 -item EQ (50\%).

When looking at the EQ subscales, the cognitive and emotional components behaved similarly to the 40-item and 28-item EQ. Indeed, for CE, genetic effects explained almost half of the variance in women's empathy, whereas heritability was modest for men. Furthermore, the shared environmental contribution was sizeable for men and absent for women. Similarly, for EE, the estimates showed no genetic influence for males and around 50\% heritability for females; prediction by the shared environment was approximately $50 \%$ for males and $0 \%$ for females. No gender differences were observed in the role of the unshared environment for either CE or EE. As expected from the wide and overlapping CI of both the genetic and environmental proportions of variance across genders, the formal chi-square test of gender heterogeneity for the 40-item and 28-item EQ, as well as for $\mathrm{CE}$ and $\mathrm{EE}$, did not reach significance. However, for all these scales, heritability was significant only for women; furthermore, for EE, the estimate of the shared environmental contribution was significant only for men. For SS, genetic and environmental proportions of variance did not differ by gender; the additive genetic and shared environmental components each contributed about $20 \%$ of total variance in both males' and females' scores, with the remaining $60 \%$ of variance in both genders due to unshared environmental factors.

\section{Discussion}

Gender differences in empathy, with women scoring higher than men on different assessment tools, are well documented in a multitude of developmental investigations (Christov-More et al., 2014), and have proven to be persistent across the lifespan (Michalska et al., 2013; O'Brien et al., 2013). Moreover, these gender differences appear to be larger with age (Eisenberg et al., 1989; Michalska et al., 2013; Van Tilburg et al., 2002).

Our results confirmed gender differences in adults' empathy levels across a range of ages, showing an apparent stability of these differences across the adult lifespan, with females scoring significantly higher on the overall scale as well as on the cognitive and emotional subdimensions, but not on the SS scale, as already found in other studies (Gouveia et al., 2012; Lawrence et al., 2004). Moreover, the absence of a gender difference in SS suggests that social factors might not be real constituents of empathy (Gouveia et al., 2012).

Such findings motivated further examination of factors involved in gender differences in adult empathy, taking advantage of the unmatched value of the twin method. Only a few investigations concern empathy subdimensions in adulthood and, more specifically, gender differences in the heritability of the trait. Our study was designed to address this gap in knowledge regarding adult empathic behavior in the Italian population, a non-North American and nonNorth European cultural and social setting with a history of relatively strong gender roles.

Although a number of investigators have found evidence of the role of heredity in empathy, in a more in-depth examination, we found possible completely different patterns of heritability of the total EQ score and of the 28-item scale, for men and women. Specifically, for males, no genetic contribution and substantial influences of both shared and individual environmental factors are likely to emerge even if these estimates are not statistically significant. Conversely, women's empathy might be predominantly driven by genetic factors and individual (non-shared) experiences. We tested for a moderating role of age to explain, at least in part, the gender differences in EQ heritability patterns; however, no moderation by age of genetic effects was found in our adult sample. 
TABLE 4

Twin Correlations for the EQ Scales by Zygosity and Gender

\begin{tabular}{|c|c|c|c|c|c|}
\hline \multirow[b]{2}{*}{ EQ scales } & \multicolumn{5}{|c|}{ Cross-twin/within-trait correlations } \\
\hline & MZM & DZM & MZF & DZF & DZUG \\
\hline 40-item EQ & $\begin{array}{l}0.43 \\
{[0.27,0.55]}\end{array}$ & $\begin{array}{l}0.42 \\
{[0.17,0.59]}\end{array}$ & $\begin{array}{l}0.54 \\
{[0.44,0.62]}\end{array}$ & $\begin{array}{l}0.23 \\
{[0.04,0.39]}\end{array}$ & $\begin{array}{c}0.11 \\
{[-0.06,0.28]}\end{array}$ \\
\hline 28-item EQ & $\begin{array}{l}0.47 \\
{[0.33,0.59]}\end{array}$ & $\begin{array}{l}0.43 \\
{[0.17,0.61]}\end{array}$ & $\begin{array}{l}0.52 \\
{[0.41,0.61]}\end{array}$ & $\begin{array}{l}0.21 \\
{[0.02,0.38]}\end{array}$ & $\begin{array}{l}0.14 \\
{[-0.03,0.30]}\end{array}$ \\
\hline CE & $\begin{array}{l}0.47 \\
{[0.33,0.58]}\end{array}$ & $\begin{array}{l}0.36 \\
{[0.04,0.58]}\end{array}$ & $\begin{array}{l}0.49 \\
{[0.38,0.58]}\end{array}$ & $\begin{array}{l}0.10 \\
{[-0.09,0.28]}\end{array}$ & $\begin{array}{l}0.20 \\
{[0.04,0.35]}\end{array}$ \\
\hline $\mathrm{EE}$ & $\begin{array}{l}0.43 \\
{[0.27,0.55]}\end{array}$ & $\begin{array}{l}0.46 \\
{[0.22,0.62]}\end{array}$ & $\begin{array}{l}0.51 \\
{[0.40,0.60]}\end{array}$ & $\begin{array}{l}0.23 \\
{[0.04,0.40]}\end{array}$ & $\begin{array}{l}0.06 \\
{[-0.11,0.22]}\end{array}$ \\
\hline SS & $\begin{array}{l}0.38 \\
{[0.22,0.51]}\end{array}$ & $\begin{array}{l}0.30 \\
{[0.04,0.51]}\end{array}$ & $\begin{array}{l}0.43 \\
{[0.31,0.53]}\end{array}$ & $\begin{array}{l}0.35 \\
{[0.16,0.50]}\end{array}$ & $\begin{array}{l}0.07 \\
{[-0.12,0.24]}\end{array}$ \\
\hline $\begin{array}{l}\text { CE-EE } \\
\text { CE-SS } \\
\text { EE-SS }\end{array}$ & $\begin{array}{l}\text { Males } \\
0.40[0.31,0.48] \\
0.41[0.32,0.48] \\
0.41[0.33,0.49]\end{array}$ & Phenot) & $\begin{array}{l}\text { elations } \\
\text { Females } \\
0.36[0.29,0 . \\
0.33[0.26,0 . \\
0.35[0.28,0 .\end{array}$ & & \\
\hline \multicolumn{6}{|c|}{ Cross-twin/cross-trait correlations } \\
\hline & \multicolumn{2}{|c|}{ Males } & \multicolumn{2}{|c|}{ Females } & \\
\hline & $M Z$ & $\mathrm{DZ}$ & $M Z$ & $\mathrm{DZ}$ & \\
\hline CE-EE & $\begin{array}{l}0.20 \\
{[0.07,0.31]}\end{array}$ & $\begin{array}{l}0.20 \\
{[-0.02,0.37]}\end{array}$ & $\begin{array}{l}0.20 \\
{[0.10,0.29]}\end{array}$ & $\begin{array}{l}0.10 \\
{[-0.04,0.23]}\end{array}$ & \\
\hline CE-SS & $\begin{array}{l}0.26 \\
{[0.14,0.37]}\end{array}$ & $\begin{array}{l}0.22 \\
{[0.01,0.40]}\end{array}$ & $\begin{array}{l}0.16 \\
{[0.07,0.25]}\end{array}$ & $\begin{array}{l}0.05 \\
{[-0.09,0.18]}\end{array}$ & \\
\hline EE-SS & $\begin{array}{l}0.26 \\
{[0.13,0.37]}\end{array}$ & $\begin{array}{l}0.25 \\
{[0.05,0.40]}\end{array}$ & $\begin{array}{l}0.22 \\
{[0.13,0.31]}\end{array}$ & $\begin{array}{l}0.10 \\
{[-0.03,0.23]}\end{array}$ & \\
\hline
\end{tabular}

Note: $\mathrm{CE}=$ cognitive empathy subscale; $\mathrm{EE}=$ emotional empathy subscale; $\mathrm{SS}=$ social skills subscale; $\mathrm{MZM}=$ monozygotic male; DZM = dizygotic male; MZF = monozygotic female; DZF = dizygotic female; DZUG = dizygotic unlike gender; $\mathrm{MZ}=$ monozygotic; $\mathrm{DZ}=$ dizygotic.

Cross-twin/within-trait correlations are between twins- 1 and twins- 2 samples for the same scale. Phenotypic correlations are between different subscales of the 28-item EQ in twins as individuals. Cross-twin/cross-trait correlations are between different subscales of the 28 -item EQ in different twins within pairs (i.e., one subscale in twins-1 sample and another subscale in twins-2 sample, and vice versa).

Numbers in square brackets are $95 \%$ confidence intervals.

\section{TABLE 5}

Genetic and Environmental Proportions of Variance for the EQ Scales by Gender

\begin{tabular}{|c|c|c|c|c|c|c|}
\hline \multirow[b]{2}{*}{ EQ scales } & \multicolumn{3}{|c|}{ Males } & \multicolumn{3}{|c|}{ Females } \\
\hline & $A$ & C & $E$ & $A$ & C & $E$ \\
\hline 40-item EQ & $\begin{array}{l}0.04 \\
{[0.00,0.53]}\end{array}$ & $\begin{array}{l}0.40 \\
{[0.00,0.55]}\end{array}$ & $\begin{array}{l}0.56 \\
{[0.43,0.70]}\end{array}$ & $\begin{array}{l}0.53 \\
{[0.26,0.61]}\end{array}$ & $\begin{array}{l}0.00 \\
{[0.00,0.24]}\end{array}$ & $\begin{array}{l}0.47 \\
{[0.39,0.57]}\end{array}$ \\
\hline 28-item EQ & $\begin{array}{l}0.10 \\
{[0.00,0.59]}\end{array}$ & $\begin{array}{l}0.40 \\
{[0.00,0.59]}\end{array}$ & $\begin{array}{l}0.50 \\
{[0.38,0.63]}\end{array}$ & $\begin{array}{l}0.49 \\
{[0.22,0.59]}\end{array}$ & $\begin{array}{l}0.00 \\
{[0.00,0.24]}\end{array}$ & $\begin{array}{l}0.51 \\
{[0.41,0.61]}\end{array}$ \\
\hline CE & $\begin{array}{l}0.26 \\
{[0.00,0.58]}\end{array}$ & $\begin{array}{l}0.21 \\
{[0.00,0.53]}\end{array}$ & $\begin{array}{l}0.53 \\
{[0.41,0.66]}\end{array}$ & $\begin{array}{l}0.47 \\
{[0.26,0.57]}\end{array}$ & $\begin{array}{l}0.00 \\
{[0.00,0.17]}\end{array}$ & $\begin{array}{l}0.53 \\
{[0.43,0.64]}\end{array}$ \\
\hline EE & $\begin{array}{l}0.00 \\
{[0.00,0.49]}\end{array}$ & $\begin{array}{l}0.47 \\
{[0.01,0.58]}\end{array}$ & $\begin{array}{l}0.53 \\
{[0.41,0.67]}\end{array}$ & $\begin{array}{l}0.49 \\
{[0.24,0.58]}\end{array}$ & $\begin{array}{l}0.00 \\
{[0.00,0.22]}\end{array}$ & $\begin{array}{l}0.51 \\
{[0.42,0.62]}\end{array}$ \\
\hline SS & $\begin{array}{l}0.25 \\
{[0.00,0.53]}\end{array}$ & $\begin{array}{l}0.16 \\
{[0.00,0.46]}\end{array}$ & $\begin{array}{l}0.59 \\
{[0.47,0.75]}\end{array}$ & $\begin{array}{l}0.19 \\
{[0.00,0.50]}\end{array}$ & $\begin{array}{l}0.23 \\
{[0.00,0.46]}\end{array}$ & $\begin{array}{l}0.58 \\
{[0.48,0.69]}\end{array}$ \\
\hline
\end{tabular}

Note: $\mathrm{CE}=$ cognitive empathy subscale; $\mathrm{EE}=$ emotional empathy subscale; $\mathrm{SS}=$ social skills subscale; $\mathrm{A}=$ additive genetic variance; $\mathrm{C}=$ shared environmental variance; $E$ = unshared environmental variance.

Numbers in square brackets are $95 \%$ confidence intervals.

Moreover, because empathy on the EQ is a complex trait, we investigated whether any of its subdimensions had a primary role in this potential pattern. The heritability analyses of the EQ subscales indicated that the possible gender differences in the heritability of empathy might be driven by the cognitive and emotional components, whereas SS might have a similar gene-environment architecture across men and women; this latter finding, if confirmed in future studies, might strengthen the hypothesis that SS are not a core component of empathy; indeed, SS are not part of the many scholars' definitions of empathy (e.g., Batson et al., 2004; Eisenberg \& Fabes, 1998).

The gender differences in heritability patterns that seem to emerge in this study might mirror the gender differences in level of empathy and might be consistent with theoretical propositions from a phylogenetic perspective that we would like to suggest in purely speculative terms. From this perspective, the bond between mother and offspring is one 
of the key factors for survival. The quality of this bond is essential, and its adaptive value is important across different species. We can assume that behavioral traits with a highly adaptive value can be preserved by natural selection. A strong bond between mother and offspring might therefore become rather widespread across species, and empathy, at least in its cognitive and affective facets, could be a means to assure a potentially higher quality of such bond. Women might be then influenced by genetics (phylogenetic memory) and by individual experiences (necessarily involving the 'quality' of the relationship with another individual that might be originating from the relationship with offspring), whereas our data seem to show a different scenario for men.

The phylogenetic approach would provide an interesting framework in the case of significant results, but it would be even more complex to provide another likely explanation for a completely different causal pathway for men and women. Indeed, we think that there could be other possible reasons for this potential pattern of results. In particular, there are findings regarding the theme of a different approach by men and women to the 'context' experienced, which might ultimately lead to diverging patterns in the 'response' provided. There is, in fact, speculation regarding socio-biological differences between males and females, with biological hereditary differences sometimes manifesting themselves to a greater degree in social behavior rather than in biological indicators (Cullen et al., 2016). Developmental analyses have also shown that heritability is only meaningful in the specific context in which the trait is investigated, and therefore that heritability estimates might be influenced by the tool and procedures of the investigations (Knafo \& Uzefovsky, 2013). Consequently, the measure of empathy and the type of recruitment (voluntary) might have affected our findings, although these influences cannot give an exhaustive explanation of the gender differences detected. In particular, we cannot exclude the possibility that, because empathy is a prosocial trait in which the tendency to volunteer might play a key role, the method of recruitment might have affected the sample composition and thus the heritability patterns found in this study. In other words, it is possible that the heritability architecture of empathy might be different in the sample that was not obtained through a request for volunteers. Moreover, social motivation - which appears to differ between males and females - is considered as one major driving force behind developmental gender differences in social capabilities such as empathy (e.g., Chevallier et al., 2012). Thus, perhaps environmental influences related to gender, and in particular adults' social motives (e.g., in relation to work choice, career, and family planning), continue to be intertwined with genetics and to reinforce differences between adult men and women. Based on the aforementioned theories and empirical findings, it is important to consider not only the study context itself (e.g., the use of a questionnaire survey, the way of administering it, and the recruitment procedure), but also (and perhaps of more importance) how the cultural setting and gender-typed culturally mediated social motivations interact with genetics in adulthood.

As previously noted, from childhood, males and females are confronted with different social stimuli and cultural expectations, and these experiences might be reflected in social experiences in adult life. In the Italian cultural context, specifically young girls have long been pressured by parents and family to do their best to help family members (Confalonieri et al., 2010; Olivari et al., 2015), this could have contributed to lessen variability across families in women's social motivation compared to men and, consequently, shared environmental variance in empathy among adult females. This, in turn, could have made the genetic component of empathy more easily detectable for women. On the other hand, given that males are not expected to be as empathic as females, socialization toward empathy may vary more across families for them.

If the gender differences in empathy heritability found in this study are replicated and results are significant in future larger studies, it would be of interest to test whether and which environmental experiences and social genderspecific motivations moderate the genetic component of empathy. We are aware that this same heritability patterns might not apply to other populations in different social and cultural environments; however, robust inter-cultural comparisons are not possible at the moment, given the scarcity of available evidences from twin studies on adult empathy in other countries. Nonetheless, we cannot exclude the existence of specific psychosocial confounding or moderating factors that were not considered in our analyses and that could, once taken into account in the modeling, mitigate the observed differences.

Previous twin studies on adults' and young adults' empathy (e.g., Davis et al., 1994; Hatemi et al., 2015; Hur, 2007; Rushton, 2004; Rushton et al., 1984), as well as a recent genome-wide meta-analysis by Warrier and colleagues (2017), found significant heritability estimates for the trait or for specific empathy components, with the remaining variance explained by individual environment only. However, to our knowledge, the only twin study that investigated the gene-environment architecture of adult empathy using a gender-stratified approach is the study by Hatemi and colleagues (2015). Their results, defined as 'preliminary' by the authors, are inconsistent with ours, with individual differences in men's empathy largely due to genetic influences, and differences in women's empathy almost entirely explained by non-shared environmental factors or error. Possible reasons for such conflicting results might be found in the different cultural and social background (Italy vs. Australia) and recruitment strategy of the Hatemi and colleagues' study. In particular, as already highlighted above, the recruitment strategy (ours was completely voluntary, that of Hatemi's was based on incentives) draws attention to possible influences on study involvement that may 
reflect gender differences in participation choice, and may ultimately have a different impact on the estimates of genetic and environmental effects in the two genders for the trait under study. In addition, Hatemi et al. (2015) used a shortened version of the EQ and did not examine gender differences for the three subscales. The aforementioned divergent results indicate that further cross-cultural comparisons with similar measures of empathy (and the same subscales) are needed to identify factors contributing to gender differences in the genetic and environmental bases of empathy.

Finally, there is evidence from non-twin studies, as in the model proposed by Decety and Moriguchi (2007), that cognitive and affective constituents of empathy are intertwined and jointly produce the experience of human empathy. Our results are in line with and extend this evidence in several ways. Indeed, we found a substantial correlation between not only the cognitive and the emotional components of empathy, but also between these components and the SS component. Furthermore, the observed intercorrelations among the subdimensions were similar for males and females, suggesting that there may be no gender difference in the co-manifestation of these different empathic (or empathy-related) skills.

Finally, taking advantage of the twin nature of our study sample, we also estimated cross-twin/cross-trait correlations in $\mathrm{MZ}$ versus $\mathrm{DZ}$ pairs for all three empathy facets, and derived evidence suggesting a possible genetic correlation between these facets only in females. This issue could be further investigated and better estimated in future studies on larger samples by using a multivariate twin model.

\section{Limitations and Strengths}

This is one of the few twin studies investigating empathy in adulthood and, to our knowledge, the second twin study addressing gender differences in the heritability of empathy. The sample size of this study is higher compared to previous investigations that made use of the ITR; nevertheless, we failed to reach statistical significance when formally testing gender differences in the genetic and environmental components of the targeted empathic traits, even if the point estimates of these components varied remarkably between men and women. Therefore, it would be desirable to replicate the investigation on a larger sample — and using as well a different assessment tool not based on self-report possibly taking into account additional confounders or specific potential moderators of the effects (e.g., social status, family composition, and job experience) that we were not able to consider in the present work. Furthermore, to better analyze EE, it would be appropriate in a future study to administer a measure of personal distress (a self-oriented, aversive reaction to another's emotion or perceived need or emotional state; see Batson, 1991) in order to address selforiented, empathy-related emotion.

\section{Conclusions}

There is a need to better understand the bases of individual differences in empathy. Our findings suggest possible gender-specific innate and environmental contributions to the trait. These analytic differences, if replicated, might be exploited in the planning of empathy promotion interventions. In this respect, it would be worth thinking of different approaches to promote empathy as a strong social catalyst, sustaining empathic behavior in different social and work settings where it produces positive results for individuals' and societal health and wellbeing (Mathews \& CollinVézina, 2016; Saffran, 2014; Shen, 2015). Should the results of our work be confirmed in future studies, they would provide valuable evidence for the design of educational programs for use with young children; in particular for boys (who tend to be lower in empathy than girls; Eisenberg \& Fabes, 1998), to shape and enhance their empathic behavior later in life.

\section{Acknowledgments}

We are grateful to Cristina D'Ippolito for her skillful technical assistance in manuscript formatting and database management. We also thank all the twins who participated in this survey. This research did not receive any specific grants from any funding agencies in the public, commercial, or not-for-profit sector.

\section{Conflict of Interest}

None.

\section{References}

Baron-Cohen, S. (2002). The extreme male brain theory of autism. Trends in Cognitive Sciences, 6, 248-254.

Baron-Cohen, S. (2009). Autism: The empathizingsystemizing (E-S) theory. Annals of the New York Academy of Sciences, 1156, 68-80.

Baron-Cohen, S., \& Wheelwright, S. (2004). The empathy quotient: An investigation of adults with Asperger syndrome or high functioning autism, and normal sex differences. Journal of Autism and Developmental Disorders, 34, 163-175.

Baron-Cohen, S., Wheelwright, S., Skinner, R., Martin, J., \& Clubley, E. (2001). The autism-spectrum quotient (AQ): Evidence from Asperger syndrome/highfunctioning autism, males and females, scientists and mathematicians. Journal of Autism and Developmental Disorders, 31, 5-17.

Batson, C. D. (1991). The altruism question: Toward a socialpsychological answer. Hillsdale, NJ: Lawrence Erlbaum Associates.

Batson, C. D., Ahmad, N., \& Stocks, E. L. (2004). Benefits and liabilities of empathy induced altruism. In A. G. Miller (Ed.), The social psychology of good and evil (pp. 359-385). New York: Guilford Press. 
Berthoz, S., Wessa, M., Kedia, G., Wicker, B., \& Grezes, J. (2008). Cross-cultural validation of the empathy quotient in a French-speaking sample. The Canadian Journal of Psychiatry, 53, 469-477.

Blair, R. J. (2005). Responding to the emotions of others: Dissociating forms of empathy through the study of typical and psychiatric populations. Consciousness and Cognition, 14, 698-718.

Brescianini, S., Fagnani, C., Toccaceli, V., Medda, E., Nisticò, L., D'Ippolito, C., ... Stazi, M. A. (2013). An update on the Italian Twin Register: Advances in cohort recruitment, project building and network development. Twin Research and Human Genetics, 16, 190-196.

Bryant, B. (1982). An index of empathy for children and adolescents. Child Development, 53, 413-425.

Burkhart, J. M., Fehr, E., Efferson, C., \& van Schaik, C. P. (2007). Other-regarding preferences in a non-human primate: Common marmosets provision food altruistically. Proceedings of the National Academy Science, 104, 1976219766.

Chakrabarti, B., \& Baron-Cohen, S. (2013). Understanding the genetics of empathy and the autistic spectrum. In S. BaronCohen, H. Tager-Flusberg, \& M. V. Lombardo (Eds.), Understanding other minds: Perspectives from developmental socialneuroscience (pp. 326-342). Oxford, UK: Oxford University Press.

Chevallier, C., Kohls, G., Troiani, V., Brodkin, E. S., \& Schultz, R. T. (2012). The social motivation theory of autism. Trends in Cognitive Sciences, 16, 231-239.

Christov-Moore, L., Simpson, E. A., Coudé, G., Grigaityte, K., Iacoboni, M., \& Ferrari, P. F. (2014). Empathy: Gender effects in brain and behavior. Neuroscience \& Biobehavioral Reviews, 4, 604-627.

Confalonieri, E., Bacchini, D., Olivari, M. G., Affuso, G., Tagliabue, S., \& Miranda, M. C. (2010). Adolescenti e stili educativi genitoriali. Quale percezione? Psicologia dell'Educazione, 4, 9-27.

Cronin, K. A. (2012). Prosocial behaviour in animals: The influence of social relationships, communication and rewards. Animal Behaviour, 84, 1085-1093.

Cullen, M. R., Baiocchi, M., Eggleston, K., Loftus, P., \& Fuchs, V. (2016). The weaker sex? Vulnerable men and women's resilience to socio-economic disadvantage. SSM-Population Health, 2, 512-524.

Davis, M. H., Luce, C., \& Kraus, S. J. (1994). The heritability of characteristics associated with dispositional empathy. Journal of Personality, 62, 369-391.

Decety, J., \& Jackson, P. L. (2004). The functional architecture of human empathy. Behavioral and Cognitive Neuroscience Reviews, 3, 71-100.

Decety, J., \& Lamm, C. (2006). Human empathy through the lens of social neuroscience. Scientific World Journal, 6, $1146-1163$.

Decety, J., \& Moriguchi, Y. (2007). The empathic brain and its dysfunction in psychiatric populations: Implications for intervention across different clinical conditions. BioPsychoSocial Medicine, 1, 22.
DeVellis, R. F. (2012). Scale development: Theory and applications. Los Angeles, CA: Sage Publications.

de Waal, F. B. (2008). Putting the altruism back into altruism: The evolution of empathy. Annual Review of Psychology, 59, 279-300.

de Waal, F. B. (2012). The antiquity of empathy. Science, 336, 874-876.

Dimitrijevic, A., Hanak, N., Vukosavljevic-Gvozden, T., \& Opacic, G. (2012). Psychometric properties of the Serbian version of the Empathy Quotient (S-EQ). Psihologija, 45, 257-276.

Duan, C., \& Hill, C. E. (1996). The current state of empathy research. Journal of Counseling Psychology, 43, 261-274.

Eisenberg, N., \& Fabes, R. A. (1998). Prosocial development. In W. Damon (Series Ed.) \& N. Eisenberg (Vol. Ed.), Handbook of child psychology. Vol. 3: Social, emotional, and personality development (5th ed., pp. 701-778). New York: Wiley.

Eisenberg, N., Fabes, R. A., Schaller, M., \& Miller, P. A. (1989). Sympathy and personal distress: Development, gender differences, and interrelations of indexes. New Directions for Child Development, 44, 107-126.

Eisenberg, N., Guthrie, I. K., Cumberland, A., Murphy, B. C., Shepard, S. A., Zhou, Q., \& Carlo, G. (2002). Prosocial development in early adulthood: A longitudinal study. Journal of Personality and Social Psychology, 82, 993-1006.

Eisenberg, N., Guthrie, I. K., Murphy, B. C., Shepard, S. A., Cumberland, A., \& Carlo, G. (1999). Consistency and development of prosocial dispositions: A longitudinal study. Child Development, 70, 1360-1372.

Eisenberg, N., \& Lennon, R. (1983). Gender differences in empathy and related capacities. Psychological Bulletin, 94, 100131.

Eisenberg, N., \& Miller, P. A. (1987). The relation of empathy to prosocial and related behaviors. Psychological Bulletin, $101,91-119$.

Gadermann, A. M., Guhn, M., \& Zumbo, B. D. (2012). Estimating ordinal reliability for likert-type and ordinal item response data: A conceptual, empirical, and practical guide. Practical Assessment, Research and Evaluation, 17, $1-13$.

Gouveia, V. V., Milfont, T. L., Gouveia, R. S., Neto, J. R., \& Galvão, L. (2012). Brazilian-Portuguese empathy quotient: Evidences of its construct validity and reliability. Spanish Journal of Psychology, 15, 777-782.

Gregory, A. M., Light-Häusermann, J. H., Rijsdijk, F., \& Eleym, T. C. (2009). Behavioral genetic analyses of prosocial behavior in adolescents. Developmental Science, 12, 165-174.

Groen, Y., Fuermaier, A. B., Den Heijer, A. E., Tucha, O., \& Althaus, M. (2015). The empathy and systemizing quotient: The psychometric properties of the Dutch version and a review of the cross-cultural stability. Journal of Autism and Developmental Disorders, 45, 2848-2864.

Hatemi, P. K., Smith, K., Alford, J. R., Martin, N. G., \& Hibbing, J. R. (2015). The genetic and environmental foundations of political, psychological, social, and economic 
behaviors: A panel study of twins and families. Twin Research and Human Genetics, 18, 243-255.

Hooper, D., Coughlan, J., \& Mullen, M. R. (2008). Structural equation modelling: Guidelines for determining model fit. The Electronic Journal of Business Research Methods, 6, 5360.

Hu, L. T., \& Bentler, P. M. (1999). Cutoff criteria for fit indexes in covariance structure analysis: Conventional criteria versus new alternatives. Structural Equation Modeling: A Multidisciplinary Journal, 6, 1-55.

Hur, Y. M. (2007). Evidence for non-additive genetic effects on Eysenck personality scales in South Korean twins. Twin Research and Human Genetics, 10, 373-378.

Hur, Y. M., \& Craig, J. M. (2013). Twin registries worldwide: An important resource for scientific research. Twin Research and Human Genetics, 16, 1-12.

Kim, J., \& Lee, S. J. (2010). Reliability and validity of the Korean version of the empathy quotient scale. Psychiatry Investigation, 7, 24-30.

Klemmensen, R., Hobolt, S. B., Dinesen, P. T., Skytthe, A., \& Nørgaard, A. S. (2012). The Danish political twin study: Political traits in Danish twins and the general population. Twin Research and Human Genetics, 15, 74-78.

Knafo, A., \& Uzefovsky, F. (2013). Variantion in empathy. The interplay of genetic and environmental factors. In M. Legerstee, D. W. Haley, \& M. H. Bornstein (Eds.), The infant mind: Origins of the social brain (pp. 97-122). New York, NY: Guilford Publications.

Knafo, A., Zahn-Waxler, C., Van Hulle, C., Robinson, J. L., \& Rhee, S. H. (2008). The developmental origins of a disposition toward empathy: Genetic and environmental contributions. Emotion, 8, 737-752.

Lawrence, E. J., Shaw, P., Baker, D., Baron-Cohen, S., \& David, A. S. (2004). Measuring empathy: Reliability and validity of the empathy quotient. Psychological Medicine 34, 911-919.

Mathews, B., \& Collin-Vézina, D. (2016). Child sexual abuse: Raising awareness and empathy is essential to promote new public health responses. Journal of Public Health Policy, 37, 304-314.

Michalska, K. J., Kinzler, K. D., \& Decety, J. (2013). Agerelated sex differences in explicit measures of empathy do not predict brain responses across childhood and adolescence. Developmental Cognitive Neuroscience, 3, 22-32.

Muncer, S. J., \& Ling, J. (2006). Psychometric analysis of the empathy quotient (EQ) scale. Personality and Individual Differences, 40, 1111-1119.

Neale, M. C., Boker, S. M., Xie, G., \& Maes, H. H. (2006). Mx: Statistical modeling (7th ed.). Richmond, VA: Department of Psychiatry, Virginia Commonwealth University.

Neale, M. C., \& Cardon, L. R. (1992). Methodology for genetic studies of twins and families. Dordrecht, the Netherlands: Kluwer Academic Publishers.

O’Brien, E., Konrath, S. H., Grühn, D., \& Hagen, A. L. (2013). Empathic concern and perspective taking: Linear and quadratic effects of age across the adult life span. The Journals of Gerontology. Series B, Psychological Sciences and Social Sciences, 68, 168-175.
Olivari, M. G., Hertfelt Wahn, E., Maridaki-Kassotaki, K., Antonopoulou, K., \& Confalonieri, E. (2015). Adolescent perceptions of parenting styles in Sweden, Italy and Greece: An exploratory study. Europe's Journal of Psychology, 11, 244-258.

Picardi, A., Fagnani, C., Medda, E., Toccaceli, V., Brambilla, P., \& Stazi, M. A. (2015). Genetic and environmental influences underlying the relationship between autistic traits and temperament and character dimensions in adulthood. Comprehensive Psychiatry, 58, 178-188.

Preston, S. D., \& de Waal, F. B. (2002). Empathy: Its ultimate and proximate bases. Behavioral and Brain Sciences, 25, 120.

Preti, A., Vellante, M., Baron-Cohen, S., Zucca, G., Petretto, D. R., \& Masala, C. (2011). The empathy quotient: A crosscultural comparison of the Italian version. Cognitive Neuropsychiatry, 16, 50-70.

Purcell, S. (2002). Variance components models for geneenvironment interaction in twin analysis. Twin Research, 5, 554-571.

Rushton, J. P. (2004). Genetic and environmental contributions to pro-social attitudes: A twin study of social responsibility. Proceedings of the Royal Society B: Biological Sciences, 271, 2583-2585.

Rushton, J. P., Fulker, D. W., Neale, M. C., Blizard, R. A., \& Eysenck, H. J. (1984). Altruism and genetics. Acta Geneticae Medicae et Gemellologiae, 33, 265271.

Saffran, L. (2014). 'Only connect': The case for public health humanities. Medical Humanities, 40, 105-110.

Saudino, K. J., Carter, A. S., Purper-Ouakil, D., \& Gorwood, P. (2008). The etiology of behavioral problems and competencies in very young twins. Journal of Abnormal Psychology, $117,48-62$.

Shen, L. (2015). Targeting smokers with empathy appeal antismoking public service announcements: A field experiment. Journal of Health Communication, 20, 573580.

Sucksmith, E., Allison, C., Baron-Cohen, S., Chakrabarti, B., \& Hoekstra, R. A. (2013). Empathy and emotion recognition in people with autism, first-degree relatives, and controls. Neuropsychologia, 51, 98-105.

Toccaceli, V., Fagnani, C., Gigantesco, A., Brescianini, S., D’Ippolito, C., \& Stazi, M. A. (2014). Attitudes and willingness to donate biological samples for research among potential donors in the Italian Twin Register. Journal of Empirical Research on Human Research Ethics, 9, 39-47.

Van Tilburg, M. A. L., Unterberg, M. L., \& Vingerhoets, A. J. J. M. (2002). Crying during adolescence: The role of gender, menarche, and empathy. British Journal of Developmental Psychology, 20, 77-87.

Vellante, M., Baron-Cohen, S., Melis, M., Marrone, M., Petretto, D. R., Masala, C., \& Preti, A. (2013). The 'reading the mind in the eyes' test: Systematic review of psychometric properties and a validation study in Italy. Cognitive Neuropsychiatry, 18, 326-354. 
Volbrecht, M. M., Lemery-Chalfant, K., Aksan, N., ZahnWaxler, C., \& Goldsmith, H. H. (2007). Examining the familial link between positive affect and empathy development in the second year. The Journal of Genetic Psychology, 168, 105-129.

Von Horn, A., Backman, L., Davidsson, T., \& Hansen, S. (2010). Empathizing, systemizing and finger length ratio in a Swedish sample. Scandinavian Journal of Psychology, 51, 31-37.

Wakabayashi, A., Baron-Cohen, S., Uchiyama, T., Yoshida, Y., Kuroda, M., \& Wheelwright, S. (2007). Empathizing and systemizing in adults with and without autism spectrum conditions: Cross-cultural stability. Journal of Autism and Developmental Disorders, 37, 1823-1832.

Warrier, V., Grasby, K. L., Uzefovsky, F., Toro, R., Smith, P., Chakrabarti, B., \& Baron-Cohen, S. (2017). Genome-wide meta-analysis of cognitive empathy: Heritability, and correlates with sex, neuropsychiatric conditions and cognition. Molecular Psychiatry. Advance online publication.

Wright, D. B., \& Skagerberg, E. M. (2012). Measuring empathizing and systemizing with a large US sample. PLoS ONE, 7, e31661.
Zahn-Waxler, C., Radke-Yarrow, M., Wagner, E., \& Chapman, M. (1992). Development of concern for others. Developmental Psychology, 28, 126-136.

Zahn-Waxler, C., Robinson, J. L., \& Emde, R. N. (1992). The development of empathy in twins. Developmental Psychology, 28, 1038-1047.

Zahn-Waxler, C., Schiro, K., Robinson, J. L., Emde, R. N., \& Schmitz, S. (2001). Empathy and prosocial patterns in young $\mathrm{MZ}$ and DZ twins. In R. N. Emde \& J. K. Hewitt (Eds.), Infancy to early childhood: Genetic and environmental influences on developmental change (pp. 141-162). New York, NY: Oxford University Press.

Zeyer, A., Boelsterli, K., Brovelli, D., \& Odermatt, F. (2012). Brain type or sex differences? A structural equation model of the relation between brain type, sex, and motivation to learn science. International Journal of Science Education, 34, 779-802.

Zumbo, B. D., Gadermann, A. M., \& Zeisser, C. (2007). Ordinal versions of coefficients alpha and theta for Likert rating scales. Journal of Modern Applied Statistical Methods, 6, 21-29. 